\title{
PENURUNAN KADAR BESI (Fe) DAN MANGAN (Mn) PADA AIR SUMUR GALI DENGAN MENGGUNAKAN METODE AERASI DAN FILTRASI DI SUKODONO SIDOARJO
}

\author{
Ismy Nur Fuadatul Azkiyah **) dan Joko Sutrisno *)
}

\begin{abstract}
Abstrak
Kadar Fe dan kadar Mn pada air sumur gali di daerah Sukodono Sidoarjo yaitu 19,80 mg/l dan 7,65 mg/l . Kadar Fe dan Mn tersebut belum memenuhi standar baku PERMENKES No 490 tentang air bersih. Hal tersebut dapat menyebabkan beberapa gangguan pada kesehatan. Oleh karena itu perlu dilakukan pengolahan. Pada penelitian ini yang dilakukan adalah aerasi dan filtrasi. Aerasi digunakan untuk menurunkan kadar Fe dan Mn dengan menggunakan cascade aerator dan filtrasi yang digunakan menggunakan media pasir silika dan kerikil. Parameter yang diukur pada penelitian ini adalah kadar Fe dan kadar Mn. Variabel bebas dalam penelitian ini adalah cascade aerator yaitu cascade aerator I dengan luas area $1,4 \mathrm{~m}^{2}$ kemiringan $45^{\circ}$ dan cascade aerator II dengan luas area 1,8 $\mathrm{m}^{2}$ kemiringan $30^{\circ}$. Tujuan penelitian ini adalah mengkaji kadar Fe dan kadar Mn sebelum dan sesudah perlakuan serta mengkaji pengaruh luas cascade aerator terhadap efisiensi penurunan kadar Fe dan Mn. Penelitian ini diperoleh hasil cascade aerator I dengan luas area $1,4 \mathrm{~m}^{2}$ kemiringan $45^{\circ}$ dengan rata rata penurunan sebesar 58,36\% untuk kadar Fe dan 28,05 $\%$ untuk kadar Mn dan cascade aerator II dengan luas area cascade 1,8 $\mathrm{m}^{2}$ kemiringan $30^{\circ}$ dengan rata rata penurunan sebesar 72,52 \% untuk kadar Fe dan 52,20\% untuk kadar Mn. Kesimpulan dari penelitian ini cascade aerator II dengan luas area cascade $1,8 \mathrm{~m}^{2}$ kemiringan $30^{\circ}$ dapat menurunkan Fe dan Mn lebih baik dibanding cascade aerator I dengan luas area 1,4 $\mathrm{m}^{2}$ kemiringan $45^{\circ}$.
\end{abstract}

Kata Kunci : Cascade Aerator, Filtrasi, Besi, Mangan

\section{PENDAHULUAN}

Kandungan $\mathrm{Fe}$ dan $\mathrm{Mn}$ dalam air menyebabkan warna air berubah menjadi kuning-coklat setelah beberapa saat kontak dengan udara, di samping dapat mengganggu kesehatan dan menimbulkan bau yang kurang enak serta menyebabkan warna kuning pada diding bak serta bercak-bercak kuning pada pakaian (Erlani,2011).

Upaya untuk mengatasi itu dirancanglah sebuah alat yang dapat digunakan untuk mengolah air sumur dijadikan air bersih. Erlani (2011) telah melakukan penelitian terhadap penurunan kadar besi (Fe) dengan metode cascade aerator, didapatkan bahwa cascade aerator dengan luas cascade $1,8 \mathrm{~m}^{2}$ dan pengendapan selama 3 jam lebih baik, dengan rata rata persentase 95,48 \% dibanding dengan cascade aerator dengan luas cascade $4,5 \mathrm{~m}^{2}$ dan pengendapan 3 jam dengan persentase $72,09 \%$. Sudiati (2000) penurunan kadar besi ( $\mathrm{Fe}$ ) dan mangan ( $\mathrm{Mn})$ dengan metode cascade aerator dan rapid sand filter didapatkan bahwa cascade aerator 12 step lebih baik menyerap oksigen dengan efisiensi penurunan kadar besi sebesar 1,705-2,83\% sedangkan untuk cascade aerator dengan 7 step dapat menyerap oksigen dengan efisiensi penurunan kadar besi sebesar 0,512 - 0,862 $\%$ yang kemudian hal ini didukung dengan adanya penggunaan filter dimana kadar besi dapat diturunkan sampai $99 \%$. Winda (2003) penurunan besi (Fe) dan Mangan (Mn) menggunakan cascade aerator dan Rapid Sand Filter pada air sumur gali. Penyisihan besi $(\mathrm{Fe})$ dan Mangan ( $\mathrm{Mn}$ ) paling tinggi pada cascade aerator $39,4 \%$ untuk $\mathrm{Fe}$ dan $97,1 \%$ untuk $\mathrm{Mn}$.

Pada penelitian ini dipilih teknik aerasi bentuk cascade aerator dengan pertimbangan bahwa teknis ini cukup sederhana, biaya pembuatannya tidak terlalu mahal dan mudah dilaksanakan, metode ini mampu menaikkan oksigen $60-80 \%$ dari jumlah oksigen yang tertinggi pada air (Erlani,2011) .

Cascade adalah varian aerator gravitasi yang fisiknya artistik berbentuk tangga, indah dipandang, the art of aeration. Merupakan salah satu dari tipe gravity aerator yaitu jenis aerasi yang cara kerjanya berdasarkan daya gravitasi. Air yang akan diaerasi akan mengalir secara gravitasi karena beda ketinggian dari step satu ke step yang lain dalam Cascade Aerator. Pada Aerator ini air dijatuhkan ke permukaan serial undakan untuk menghasilkan turbulensi dan menimbulkan percikan indah butiran air. Proses aerasinya akan makin bagus kalau ukuran butir airnya makin kecil.

\footnotetext{
**) Mahasiswa Teknik Lingkungan

*) Dosen Teknik Lingkungan

Universitas PGRI Adi Buana Surabaya
} 
Selain itu, lapisan air tipis yang melimpas di atas undakannya juga mendukung terjadinya aerasi. Semakin luas undakannya semakin tinggi efisiensinya.

Pada tiap step akan terjadi kontak antara Fe dalam air dengan oksigen sehingga terjadi reaksi oksidasi.Pada dasarnya aerator ini terdiri atas 4-6 step, setiap step kira-kira ketinggian $30 \mathrm{~cm}$ dengan kapasitas kira-kira $0,01 \mathrm{~m}^{3} /$ detik per $\mathrm{m}^{2}$, untuk menghilangkan putaran (turbulen) guna menaikkan efisiensi aerasi, hambatan sering ditepi peralatan pada setiap step (Benny ,2010).

Kelebihan dan Kekurangan Cascade Aerator : Headloss lebih rendah, tidak memerlukan perawatan, teknis cukup sederhana, biaya pembuatan tidak terlalu mahal dan kekurangannya adalah memerlukan tempat yang cukup luas.

Filtrasi merupakan salah satu pengolahan air secara fisik.Filtrasi merupakan proses pemisahan antara padatan dan koloid dengan cairan. Proses penyaringan bisa juga merupakan proses awal (Primary Treatment) (Sulastri,2013).

1. Pasir Kuarsa/Silika

Merupakan hasil dari pelapukan bebatuan yang mengandung mineral utama seperti kuarsa dan feldspar. Kegunaan Pasir adalah untuk menghilangkan sifat fisik air, seperti kekeruhan/air berlumpur dan menghilangkan bau pada air.Pada umumnya pasir digunakan pada tahap awal sebagai saringan dalam pengolahan air kotor menjadi air bersih.

2. Kerikil / Koral

Teknik pengolahan air bersih dengan menggunkan media kerikil/ koral sebagai media atau alat pengolahannya. Dengan menggunakan kerikil/ koral ini dalam pengolahan air bersih berfungsi untuk menangkap endapan (Sulastri, 2013).

Berdasarkan hal tersebut maka peneliti ingin menggunakan metode cascade aerator dengan memvariasikan kemiringan cascade yang dilanjutkan dengan filtrasi sederhana dengan menggunakan media pasir silika sehingga akan diharapkan memberikan hasil yang baik.

Tujuan dari penelitian ini adalah :

1. Mengetahui penurunan besi $(\mathrm{Fe})$ sebelum dan sesudah perlakuan.

2. Mengetahui penurunan mangan (Mn) sebelum dan sesudah perlakuan.
3. Mengkaji pengaruh luas area cascade aerator terhadap efesiensi penurunan $\mathrm{Fe}$ dan $\mathrm{Mn}$.

\section{METODOLOGI PENELITIAN}

Lokasi dan waktu penelitian

Lokasi penelitian yaitu di desa Ketapang

Rt : 45 Rw : 03 kecamatan Sukodono Sidoarjo.

Dan waktu penelitian di mulai dari bulan April sampai bulan Juni 2014.

\section{Variabel bebas}

Variabel bebas dalam penelitian ini adalah :

1. Cascade (tangga) sebanyak 7 step dengan luas area $1,4 \mathrm{~m}^{2}$ untuk kemiringan $45^{\circ}$. (Reaktor I)

2. Cascade (tangga) sebanyak 7 step dengan luas area $1,8 \mathrm{~m}^{2}$ untuk kemiringan $30^{\circ}$. (Reaktor II)

Sampel penelitian Sampel pada penelitian ini adalah air sumur gali di desa Ketapang No. 4 RT45/RW03 kecamatan Sukodono Sidoarjo.

Alat dan Bahan :

- Cascade aerator dari kaca

- Reaktor filtrasi

- Kerikil

- Pasir

\section{Langkah langkah Penelitian :}

1. Air sumur dimasukkan dalam bak penampung $\mathrm{I}$.

2. Kemudian dialirkan ke cascade aerator.

3. Dari cascade aerator air mengalir ke dalam bak penampung II dan didiamkan selama 10 menit.

4. Setelah itu, air dialirkan ke dalam reaktor filtrasi.

5. Dari proses filtrasi air mengalir ke dalam bak penampung III dan didiamkan selama 10 menit untuk proses pengendapan.

6. Setelah itu air sampel diambil untuk diperiksa ke laboratorium.

\section{Metode Analisis Data}

Analisis dilakukan dengan cara deskriptif yaitu untuk mengetahui penurunan dengan efisiensi (\%). 
HASIL PENELITIAN

Hasil penelitian kadar besi $(\mathrm{Fe})$ dan mangan $(\mathrm{Mn})$ sumur gali di desa Ketapang kecamatan Sukodono sebelum diolah adalah 19,80 mg/l dan 7,65 mg/l. Setelah diaerasi dan filtrasi kadar $\mathrm{Fe}$ dan Mn pada air sumur gali disajikan dalam tabel 1,2,3, dan 4 sebagai berikut :

Tabel 1. Kadar Fe dan Mn untuk reaktor I dengan cara aerasi

\begin{tabular}{|c|c|c|c|c|c|c|c|c|}
\hline \multirow[t]{2}{*}{ No } & \multicolumn{2}{|c|}{ Kadar Fe (mg/l) } & \multirow{2}{*}{$\begin{array}{c}\text { Penurunan } \\
(\mathrm{mg} / \mathrm{l})\end{array}$} & \multirow{2}{*}{$\begin{array}{l}\text { Ef } \\
\%\end{array}$} & \multicolumn{2}{|c|}{ Kadar Mn (mg/l) } & \multirow{2}{*}{$\begin{array}{c}\text { Penurunan } \\
(\mathrm{mg} / \mathrm{l})\end{array}$} & \multirow{2}{*}{$\begin{array}{l}\text { Ef } \\
\%\end{array}$} \\
\hline & awal & akhir & & & Awal & Akhir & & \\
\hline 1 & 19,80 & 11,05 & 8,75 & $44,1 \%$ & 7,65 & 5,82 & 1,83 & $23,92 \%$ \\
\hline 2 & 19,80 & 10,18 & 9,62 & $48,5 \%$ & 7,65 & 6,31 & 1,34 & $17,51 \%$ \\
\hline 3 & 19,80 & 11,50 & 8,3 & $41,9 \%$ & 7,65 & 6,11 & 1,54 & $20,13 \%$ \\
\hline \multirow[t]{2}{*}{4} & 19,80 & 9,22 & 10,58 & $\begin{array}{c}53,43 \\
\%\end{array}$ & 7,65 & 5,77 & 1,88 & $24,57 \%$ \\
\hline & \multicolumn{3}{|c|}{$\begin{array}{l}\text { Rata rata persen penurunan } \\
\text { kadar besi (Fe) dan mangan } \\
(\mathrm{Mn})\end{array}$} & $\begin{array}{c}46,98 \\
\%\end{array}$ & & & & $21,53 \%$ \\
\hline
\end{tabular}

Tabel 2. Kadar Fe dan Mn Pada Reaktor I dengan cara filtrasi

\begin{tabular}{|c|c|c|c|c|c|c|c|c|}
\hline \multirow[t]{2}{*}{ No } & \multicolumn{2}{|c|}{ Kadar Fe (mg/l) } & \multirow[t]{2}{*}{$\begin{array}{l}\text { Penurunan } \\
(\mathrm{mg} / \mathrm{l})\end{array}$} & \multirow[t]{2}{*}{$\begin{array}{l}\text { Ef } \\
\%\end{array}$} & \multicolumn{2}{|c|}{$\begin{array}{l}\text { Kadar Mn } \\
(\mathrm{mg} / \mathrm{l})\end{array}$} & \multirow[t]{2}{*}{$\begin{array}{l}\text { Penurunan } \\
(\mathrm{mg} / \mathrm{l})\end{array}$} & \multirow[t]{2}{*}{$\begin{array}{l}\text { Ef } \\
\%\end{array}$} \\
\hline & awal & akhir & & & Awal & Akhir & & \\
\hline 1 & 19,80 & 8,05 & 11,75 & $59,34 \%$ & 7,65 & 4,65 & 3,00 & $39,2 \%$ \\
\hline 2 & 19,80 & 7,64 & 12,16 & $61,41 \%$ & 7,65 & 4,19 & 3,46 & $45,2 \%$ \\
\hline 3 & 19,80 & 5,02 & 14,78 & $74,64 \%$ & 7,65 & 5,32 & 2,33 & $30,4 \%$ \\
\hline \multirow[t]{2}{*}{4} & 19,80 & 4,05 & 15,75 & $79,54 \%$ & 7,65 & 4,96 & 2,69 & $35,1 \%$ \\
\hline & \multicolumn{3}{|c|}{$\begin{array}{l}\text { Rata rata persen penurunan } \\
\text { kadar besi (Fe) dan mangan } \\
(\mathrm{Mn})\end{array}$} & $68,73 \%$ & & & & $37,47 \%$ \\
\hline
\end{tabular}

Tabel 3. Kadar Fe dan Mn Pada Reaktor II dengan cara aerasi

\begin{tabular}{|c|c|c|c|c|c|c|c|c|}
\hline \multirow[t]{2}{*}{ No } & \multicolumn{2}{|c|}{ Kadar Fe (mg/l) } & \multirow{2}{*}{$\begin{array}{l}\text { Penurunan } \\
(\mathrm{mg} / \mathrm{l})\end{array}$} & \multirow{2}{*}{$\begin{array}{l}\text { Ef } \\
\%\end{array}$} & \multicolumn{2}{|c|}{ Kadar Mn (mg/l) } & \multirow{2}{*}{$\begin{array}{c}\text { Penurunan } \\
(\mathrm{mg} / \mathrm{l})\end{array}$} & \multirow{2}{*}{$\begin{array}{l}\text { Ef } \\
\%\end{array}$} \\
\hline & awal & akhir & & & Awal & Akhir & & \\
\hline 1 & 19,80 & 10,02 & 9,78 & $49,39 \%$ & 7,65 & 6,11 & 1,54 & $20,13 \%$ \\
\hline 2 & 19,80 & 10,34 & 9,46 & $47,77 \%$ & 7,65 & 5,38 & 2,27 & $29,67 \%$ \\
\hline 3 & 19,80 & 7,50 & 12,3 & $62,1 \%$ & 7,65 & 5,66 & 1,99 & $26 \%$ \\
\hline 4 & 19,80 & 5,11 & 14,69 & $74,19 \%$ & 7,65 & 4,86 & 2,79 & $36,4 \%$ \\
\hline & $\begin{array}{l}\text { Rata } \\
\text { kada }\end{array}$ & $\begin{array}{l}\text { a perse } \\
\text { si (Fe) } \\
(\mathrm{Mr}\end{array}$ & $\begin{array}{l}\text { enurunan } \\
\text { mangan }\end{array}$ & $58,36 \%$ & & & & $28,05 \%$ \\
\hline
\end{tabular}


Tabel 4. Kadar Fe dan Mn pada reaktor II dengan cara filtrasi

\begin{tabular}{|c|c|c|c|c|c|c|c|c|}
\hline \multirow[t]{2}{*}{ No } & \multicolumn{2}{|c|}{ Kadar Fe (mg/l) } & \multirow[t]{2}{*}{$\begin{array}{c}\text { Penurunan } \\
(\mathrm{mg} / \mathrm{l})\end{array}$} & \multirow[t]{2}{*}{$\begin{array}{l}\text { Ef } \\
\%\end{array}$} & \multicolumn{2}{|c|}{$\begin{array}{c}\text { Kadar Mn } \\
(\mathrm{mg} / \mathrm{l})\end{array}$} & \multirow[t]{2}{*}{$\begin{array}{l}\text { Penurunan } \\
(\mathrm{mg} / \mathrm{l})\end{array}$} & \multirow[t]{2}{*}{$\begin{array}{l}\text { Ef } \\
\%\end{array}$} \\
\hline & awal & akhir & & & Awal & Akhir & & \\
\hline 1 & 19,80 & 7,32 & 12,48 & $63 \%$ & 7,65 & 4,05 & 3,60 & $47 \%$ \\
\hline 2 & 19,80 & 7,11 & 12,69 & $64 \%$ & 7,65 & 3,82 & 3,83 & $50 \%$ \\
\hline 3 & 19,80 & 4,05 & 15,75 & $79,5 \%$ & 7,65 & 3,67 & 3,98 & $52 \%$ \\
\hline 4 & 19,80 & 3,24 & 16,56 & $83,6 \%$ & 7,65 & 3,05 & 4,60 & $60,1 \%$ \\
\hline & $\begin{array}{l}\text { Rata } \\
\text { kadar }\end{array}$ & $\begin{array}{l}\text { perse } \\
\text { i (Fe) } \\
(\mathrm{Mn}\end{array}$ & $\begin{array}{l}\text { enurunan } \\
\text { n mangan }\end{array}$ & $\begin{array}{c}72,52 \\
\%\end{array}$ & & & & $52,20 \%$ \\
\hline
\end{tabular}

Hasil efesiensi penurunan Fe dan Mn disajikan dalam gambar 1 dan 2 dibawah ini :

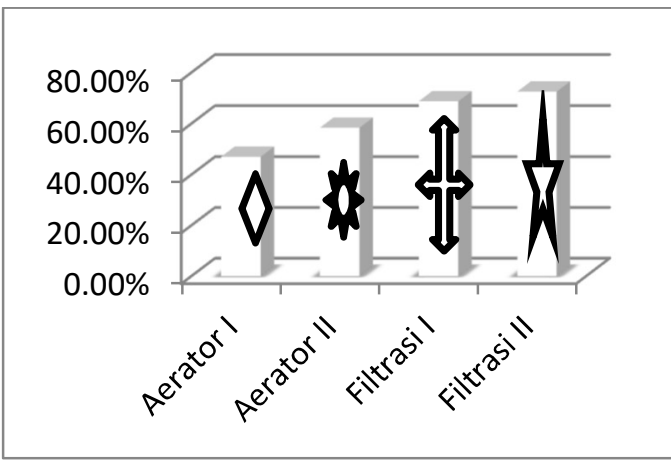

Gambar 1. Efisiensi penurunan kadar besi $(\mathrm{Fe})$ $(\mathrm{Mn})$

\section{PEMBAHASAN}

Berdasarkan hasil penelitian dengan menggunakan cascade aerator dengan luas area cascade $1,4 \mathrm{~m}^{2}$ kemiringan $45^{\circ}$, terlihat terjadi penurunan sesudah aerasi yaitu kadar besi ( $\mathrm{Fe}$ ) adalah $10,58 \mathrm{mg} / \mathrm{l}$ sampai $8,3 \mathrm{mg} / \mathrm{l}$ atau persentase penurunan antara $53,43 \%$ sampai $41,9 \%$ dan kadar mangan $(\mathrm{Mn})$ adalah $1,88 \mathrm{mg} / \mathrm{l}$ sampai $1,34 \mathrm{mg} / \mathrm{l}$ atau persentase penurunan antara $24,57 \%$ sampai $17,51 \%$. Dan luas area cascade $1,8 \mathrm{~m}^{2}$ kemiringan $30^{\circ}$ terlihat terjadi penurunan sesudah aerasi yaitu kadar besi (Fe) adalah $14,69 \mathrm{mg} / \mathrm{l}$ sampai $9,46 \mathrm{mg} / \mathrm{l}$ atau persentase penurunan antara $74,19 \%$ sampai $47,77 \%$ dan kadar mangan (Mn) adalah $2,79 \mathrm{mg} / \mathrm{l}$ sampai $1,54 \mathrm{mg} / \mathrm{l}$ atau persentase penurunan antara $36,4 \%$ sampai $20,13 \%$.

Dengan melihat hasil diatas menunjukkan terjadi penurunan sesuai dengan reaksi aerasi berikut:

$$
4 \mathrm{Fe}^{2+}+\mathrm{O}_{2}+10 \mathrm{H}_{2} \mathrm{O}=\rightarrow 4 \mathrm{Fe}(\mathrm{OH})_{3}+8 \mathrm{H}^{+}
$$

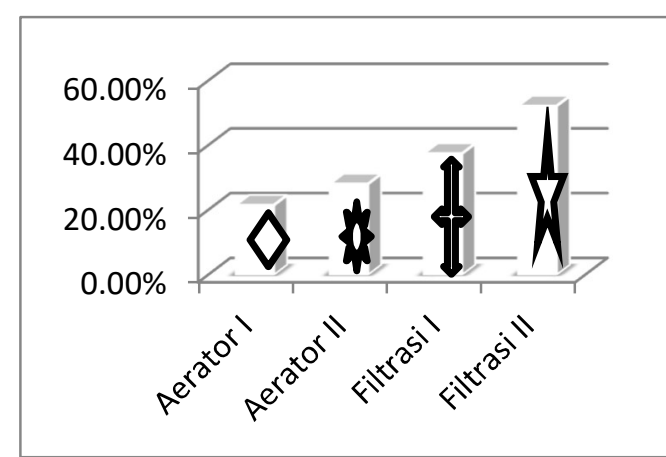

Gambar 2. Efisiensi penurunan kadar mangan

$$
2 \mathrm{Mn}^{2+}+\mathrm{O}_{2}+2 \mathrm{H}_{2} \mathrm{O}=\rightarrow 2 \mathrm{MnO}_{2}+4 \mathrm{H}^{+}
$$

Sesuai dengan reaksi tersebut, pada proses aerasi luas area cascade $1,4 \mathrm{~m}^{2}$ kemiringan $45^{\circ}$ dan luas area cascade $1,8 \mathrm{~m}^{2}$ kemiringan $30^{\circ}$ terjadi penurunan hanya saja tidak besar dan hasilnya belum memenuhi standar persyaratan peraturan PERMENKES No.490 tentang air bersih. Hal ini disebabkan oleh : kadar besi dan mangan pada air baku terlalu tinggi, debit air baku juga terlalu tinggi dan kurangnya penetrasi antara air dan oksigen, karena pada saat air mengalir dari cascade 1 sampai cascade 7 proses air kontak dengan udara kurang lama dan kemiringan cascade juga berpengaruh, dengan kemiringan tersebut air mengalir dengan cepat melewati tiap cascade, hal ini menjadi salah satu penyebab kurangnya air kontak dengan udara.

Setelah proses aerasi, proses selanjutnya ialah proses filtrasi. Proses filtrasi diharapkan menghasilkan penurunan yang optimal. Hasil 
setelah proses filtrasi untuk luas area cascade $1,4 \mathrm{~m}^{2}$ kemiringan $45^{\circ}$ adalah penurunan kadar besi ( $\mathrm{Fe}$ ) yaitu $8,05 \mathrm{mg} / \mathrm{l}$ sampai 4,05 $\mathrm{mg} / \mathrm{l}$ atau persentase penurunan antara 59,34 \% sampai 79,54 \%. Kadar mangan (Mn) yaitu $5,32 \mathrm{mg} / \mathrm{l}$ sampai $4,19 \mathrm{mg} / \mathrm{l}$ atau persentase $30,4 \%$ sampai $45,2 \%$. Dan luas area cascade $1,8 \mathrm{~m}^{2}$ kemiringan $30^{\circ}$ terlihat terjadi penurunan sesudah filtrasi, kadar besi (Fe) yaitu 7,32 mg/l sampai 3,24 $\mathrm{mg} / \mathrm{l}$ atau persentase penurunan antara $63 \%$ sampai $83,6 \%$. Kadar mangan (Mn) yaitu 4,05 mg/l sampai 3,05 $\mathrm{mg} / \mathrm{l}$ atau persentase $47 \%$ sampai $60,1 \%$.

Dengan melihat hasil diatas menunjukkan bahwa terjadi penurunan kadar besi dan mangan dengan filtrasi cukup besar dibanding dengan proses aerasi saja, hal ini karena proses filtrasi adalah proses penyaringan atau pemisahan antara padatan dan koloid dengan cairan. Filtrasi menggunakan dua media yaitu pasir silika dan kerikil. Dengan adanya dua proses pengolahan air secara aerasi dan filtrasi menunjukkan penurunan yang cukup besar dan baik .

Aerasi dan filtrasi dengan luas area cascade $1,4 \mathrm{~m}^{2}$ kemiringan $45^{\circ}$ menunjukkan adanya penurunan, dengan hasil tersebut penurunan ini sudah cukup baik, tetapi penurunan kadar besi dan mangan tersebut hasilnya jauh dari persyaratan peraturan PERMENKES No.490 tentang air bersih. Aerasi dan filtrasi dengan luas area cascade $1,8 \mathrm{~m}^{2}$ kemiringan $30^{\circ}$ mempunyai kemampuan lebih baik. Sesuai dengan hasil diatas menunjukkan bahwa penurunan lebih besar dan baik dibanding aerasi dengan luas wilayah $1,4 \mathrm{~m}^{2}$ kemiringan $45^{\circ}$. Namun penurunannya masih belum memenuhi persyaratan peraturan PERMENKES No.490 tentang air bersih dan untuk mengetahui mengapa terjadi hal seperti ini perlu penelitian lebih lanjut.

Berdasarkan dari analisa diatas terlihat bahwa setelah aerasi dengan masing masing luas area cascade yang dilanjutkan dengan filtrasi penurunannya sudah cukup baik. Hal ini disebabkan karena adanya kontak antara air dengan udara dimana semakin lama dan semakin luas permukaan air yang mengalami kontak dengan udara berarti penetrasi oksigen semakin besar sehingga oksidasi semakin baik dan juga dilanjutkan dengan proses filtrasi.

Keadaan ini sesuai dengan peneliti terdahulu Erlani (2011) telah melakukan penelitian terhadap penurunan kadar besi (Fe) dengan metode cascade aerator, didapatkan bahwa cascade aerator dengan luas wilayah
$1,8 \mathrm{~m}^{2}$ dan pengendapan 3 jam lebih baik, dengan rata rata persentase 95,48 \% dibanding dengan cascade aerator dengan luas wilayah $4,5 \mathrm{~m}^{2}$ dan pengendapan 3 jam dengan persentase $72,09 \%$. Winda (2003) penurunan besi (Fe) dan mangan (Mn) menggunakan cascade aerator dan Rapid Sand Filter pada air sumur gali. Penyisihan besi ( $\mathrm{Fe}$ ) dan mangan ( $\mathrm{Mn}$ ) paling tinggi pada cascade aerator 39,4 \% untuk besi dan 97,1\% untuk mangan.

Keadaan ini juga sesuai dengan beberapa referensi yang menyatakan bahwa salah satu cara untuk menurunkan kadar besi dan mangan adalah aerasi yang dilanjutkan dengan filtrasi. Aerasi berfungsi untuk mengoksidasi Ferro menjadi Ferri dan filtrasi yang berfungsi sebagai pemisah atau penyaring antara padatan dan koloid dengan cairan.

\section{KESIMPULAN DAN SARAN}

Dari hasil penelitian yang telah dilakukan maka dapat disimpulkan dan disarankan sebagai berikut:

\section{Kesimpulan :}

Uji kadar (Fe) dan kadar (Mn) sebelum perlakuan adalah 19,80 mg/l dan 7,65 mg/l. Cascade aerator I setelah diaerasi kadar Fe menjadi 9,22 mg/l dan kadar Mn menjadi $5,77 \mathrm{mg} / \mathrm{l}$ dan setelah difiltrasi kadar $\mathrm{Fe}$ menjadi 4,05 mg/l dan kadar Mn 4,19 mg/l.

Dengan cascade aerator II setelah diaerasi kadar Fe menjadi 5,11 mg/l dan kadar $\mathrm{Mn}$ menjadi 4,86 mg/l dan setelah di filtrasi kadar Fe menjadi 3,24 mg/l dan kadar Mn menjadi $3,05 \mathrm{mg} / \mathrm{l}$.

Cascade aerator II dengan luas area cascade $1,8 \mathrm{~m}^{2}$ kemiringan $30^{\circ}$ mendapatkan hasil lebih baik dengan rata rata penurunan sebesar $72,52 \%$ untuk kadar Fe dan 52,20 \% untuk kadar Mn dibanding dengan cascade aerator I dengan luas area $1,4 \mathrm{~m}^{2}$ kemiringan $45^{\circ}$ dengan rata rata penurunan sebesar 58,36\% untuk kadar Fe dan 28,05 \% untuk kadar Mn.

\section{Saran :}

Walaupun sudah dilakukan pengolahan dengan cascade aerator dan filtrasi tetapi masih belum memenuhi standar baku PERMENKES No 490 tentang air bersih, maka diperlukan penelitian tentang : Kemiringan cascade (tangga) ditambah lagi dengan berbagai kemiringan. Perlu dilakukan variasi waktu dalam proses pengendapan setelah melalui aerasi. Perlu dilakukan variasi besarnya debit $(Q)$ air baku. 


\section{DAFTAR PUSTAKA}

Addy, Bastian, 2009 . Penurunan Kadar Ion Besi (Fe) Dalam Air Bersih Secara Aerasi Dan Sedimentasi Dengan Menggunakan Media Magnet, Jurusan Teknik Lingkungan UNIPA Surabaya.

Alaerts, G. dan Sri Santika Sumestri. 1987. Metode Penelitian Air. Surabaya: Usaha Nasionallic Health Association.

Aliyah , 2013. Rancang Alat Pengolahan Air Sumur Menjadi Air Bersih, Jurusan Kimia Politeknik Negeri Sriwijaya Palembang.

Benny , 2007. Penurunan Kadar Besi Pada Air Sumur Secara Pneumatic System, Semarang.

Daud, Anwar, 2005. Penyediaan Air Bersih, Fakultas Kesehatan Masyarakat, Unhas. Makasar.

Eaton, Andrew. Et.al. 2005. Standard Methods for Examination of Water and Wastewater. 21st Edition. Marryland - USA : American Pub.

Erlani , 2011. Variasi Luas Wilayah Cascade Terhadap Penurunan Kadar Besi, Jurusan kesehatan Lingkungan Poltekes Makasar.

( http://en-wikipedia.or diunduh tanggal 26 Desember 2013).

Idaman , Nusa, 2010. Pembuatan Filter Untuk Menghilangkan Zat Besi Dan Mangan Di dalam Air, Jakarta.

Joeharno , 2008. Kualitas Air Berdasarkan Konstruksi Sumur Gali, Puskesmas Antang Kota Makasar.

Parulian, Alwin. 2009. Monitoring dan Analisis Kadar Aluminium (Al) dan Besi (Fe) Pada Pengolahan Air Minum PDAM Tirtanadi Sunggal. Medan : Pascasarjana - Universitas Sumatera Utara (USU).

Said, N.S dan Wahjono, H.D. 1999. Pembuatan Filter Untuk Menghilangkan Zat Besi dan Mangan Di Dalam Air. Jakarta : BPPT

Slamet, J. Soemitrat, 1994. Kesehatan Lingkungan Gajah Mada Universitiy Press, Yogyakarta.

Sudiati, K., 2000. Penurunan Kadar Besi (Fe)dengan Metode Aerasi, Sedimentasi dan Filtrasi untuk Skala Rumah Tangga di Pedesaan. Tugas Akhir Jurusan Teknik Lingkungan FTSP-ITS. Surabaya

Sugiharto, 1985. Penyediaan Air Bersih Bagi Masyarakat. Proyek Pengembangan Pendidikan Tenaga Sanitasi Pusat, Jakarta.

Sulastri , 2013. Pengaruh Ketebalan Media Filtrasi Pada Air Telaga Di Balong Panggang, Jurusan Teknik Lingkungan UNIPA Surabaya.

Winda, K. 2003. Studi penurunan Fe dan Mn dengan Menggunakan Cascade Aerator dan Rapid Sand Filter pada air Sumur Gali. Jurusan Teknik Lingkungan ITS: Surabaya.

Wordpress. 2007. Peraturan Menteri Kesehatan No. 416 Tahun 1990, (http://persembahanku.files.wordpress.com diunduh tanggal 26 Desember 2013 